\title{
COLLABORATION IN THE DESIGN AND DELIVERY OF A MENTAL HEALTH RECOVERY COLLEGE COURSE: EXPERIENCES OF STUDENTS AND
}

\section{TUTORS.}

DOI: https://doi.org/10.1080/09638237.2018.1466038

Authors:

1) Josh Cameron, School of Health Sciences, University of Brighton.

2) Angie Hart, Centre for Health Research, University of Brighton.

3) Saff Brooker, Peer Trainer, Sussex Recovery College.

4) Paul Neale, Peer Trainer, Sussex Recovery College.

5) Mair Reardon, Occupational Therapist, Sussex Partnership NHS Foundation Trust.

Corresponding author:

Josh Cameron

School of Health Sciences

University of Brighton

Robert Dodd Building

49 Darley Rd

Eastbourne

East Sussex

BN20 7UR

UK

j.cameron@brighton.ac.uk

\section{ABSTRACT}

Background: Recovery Colleges address mental health challenges using an educative approach underpinned by a collaborative recovery orientated philosophy. Research has been limited with no studies identified reporting research on the design and delivery of a specific course.

Aims: To understand how Recovery College students and tutors experience the design and delivery of a mental health Recovery College course, specifically the 'Building Resilience’ course.

Method: Thematic analysis of qualitative data related to the experience and process of collaboration in recovery college course design and delivery. Data included 13 qualitative 
individual interviews with course students and tutors and 'naturally occurring' data generated through course preparation and delivery.

Results: Findings drew attention to the centrality of: prior experience and design related to students, tutors and the course structure; co-delivery related to tutors and co-learner impacts; and to the course methods and environment.

Conclusions: Commitment to collaboration in design and delivery of Recovery College courses can mobilise the diverse experiences and expertise of tutors and students. The environment and methods of learning have a significant impact and should be considered alongside content. Boundaries between people and areas of knowledge and experience that arise can be viewed as sources of creativity that can enrich courses.

Keywords: Recovery, Recovery College, Mental Health, Collaboration, Resilience.

\section{INTRODUCTION}

The recovery concept has had a global impact on support for people facing mental health problems (Anthony, 1993; Repper \& Perkins, 2012). Underpinning values define recovery by quality of life not the presence or absence of symptoms. Key elements include focusing on strengths, nurturing hope and recruiting staff with lived experience of recovery from mental health problems. These principles have informed educational approaches to mental health known as Recovery Colleges in UK literature and Recovery Education Centres in US literature (Dunn et al., 2008; Perkins et al., 2012).

Many Recovery Colleges have developed in the last decade, notably in England but also in Scotland, Ireland, Italy, Australia and Japan (Meddings et al., 2015; Slade et al., 2014). UK development has been supported by policy commitments to recovery values (Department of Health, 2011) and the government backed Implementing Recovery through 
Organisational Change (ImROC) programme (Shepherd et al., 2014). An ImROC report

(Perkins et al., 2012) provided guidance on key Recovery College features (Figure 1).

FIGURE 1

Recovery College defining features (from Perkins et al. (2012)

Co-production between people with personal and professional experience of mental health problems Physical base with classrooms and a library where people can do their own research

Operates on college principles

Open to everyone

Uses a personal tutor system to inform, guide and advise learners

Is not a substitute for traditional assessment and treatment

Is not a substitute for mainstream colleges

Must reflect recovery principles in culture and organisation

Emphasis on student choice, placing lived experience on a par with professional expertise and use of the term student/learner rather than mental health service user or patient are all viewed as contributing to empowerment (Meddings et al., 2014; Perkins et al., 2012).

There is variation in the current wave of Recovery Colleges. With similarities to earlier US Recovery Education Centres, McCaig et al. (2014) described a Recovery College in a Scottish university that had a greater degree of independence from national health services than those in England. McCaig et al. (2014) maintained - though without formal evidence - that university involvement offers advantages by emphasising that Recovery Colleges are open to all interested in mental health recovery and by strengthening the educational as opposed to clinical ethos. Mainstream educational involvement has been reported in Australia (Gill, 2014) and in the USA (Ashcraft et al., 2006; Dunn et al., 2008). Whilst not reflecting current implementation patterns, regional survey respondents in England considered that universities may provide appropriate Recovery College locations (Kelly et al., 2017). 
Despite the open access principle there is also variation in proportions of students who are mental health staff, service users (though consistently the largest group), carers or general public (McGregor et al., 2014; Meddings et al., 2014; Zabel et al., 2016; Zucchelli \& Skinner, 2013). Recovery College courses range from one off workshops to series of sessions provided on a weekly basis for 4-8 weeks with content addressing diverse issues (see Figure 2).

FIGURE 2

\section{Recovery College course classifications principally derived from Meddings et al (2015) and McGregor at} al (2014)

Understanding recovery: sessions relating to understanding different

mental health challenges such as psychosis or self-harm, understanding medication or navigating mental health services

Rebuilding your life: telling your story, personal recovery wellness plans, improving sleep, happiness, coping with voices, mindfulness

Developing life skills: keeping well, moving towards life goals, returning to learning or employment, money management

Physical health and wellbeing: Food and mood, smoking cessation; sport and fitness Getting involved: teaching qualification (for trainers), co-production, advocacy, introduction to peer support

Because of their recent development, there is limited direct evidence for Recovery Colleges but strong evidence for underpinning components such as self-management, peer contributions to support and education and psycho-education (Meddings et al., 2015; Perkins et al., 2012; Slade et al., 2014). Students report appreciation of the general recovery approach, including co-production (Gill, 2014; Meddings et al., 2014; Meddings et al., 2015; Newman-Taylor et al., 2016; Zabel et al., 2016). However, Gill (2014) noted discontent when clinicians were considered not to be acting in a true coproduced manner. Published studies provide a useful focus on overall experiences and impacts but a need remains for more 
detailed qualitative research to elucidate specific mechanisms of change (McGregor et al., 2014; Meddings et al., 2015). No studies were identified reporting research on the design and delivery of a specific course.

This article addresses this gap by focusing on experiences of learners and tutors related to the collaborative design and delivery of a single course aiming to build resilience for mental well-being and recovery. The resilience building design and related outcomes of the project are reported elsewhere (Cameron et al., forthcoming). It was part of a wider UK research council funded project (Imagine Project, 2017). The Imagine Project was concerned with developing and learning from co-produced (involving university and community partners) ecological resilience building interventions. This 'ecological’ perspective considers that resilience emerges from both within individuals and from the world around them (Hart et al., 2007; Ungar et al., 2007).

The Imagine Project drew on social learning theory (Wenger, 1998) to inform the process and analysis of the research collaboration involving people with different forms of expertise (practitioner, academic and lived experience). In particular a Communities of Practice (CoP) approach facilitated bringing together people with different forms of knowledge. Social learning theory frames the boundaries created by such different people coming together as creative learning opportunities (Wenger-Trayner \& Wenger-Trayner, 2014). Recovery Colleges can accordingly be conceptualised as innovative because traditionally such boundary encounters have been avoided.

The specific research question this article addresses was:

How do Recovery College students, peer tutors, practitioners and academics experience the collaborative design and delivery of a mental health Recovery College course, specifically the 'Building Resilience’ course? 


\section{METHOD}

This article reports on analysis of qualitative case study data related to the experience and process of collaboration in recovery college course design and delivery. Data included 13 qualitative semi-structured individual interviews with course students (9) and tutors (4) and ‘naturally occurring’ data (Silverman, 2011) comprising items collectively or individually produced by these and other consenting participants during the course such as flip chart notes and homework documentation. Approximately 30 such items were selected for analysis, though many had been produced by multiple participants (such as post-it notes on a flip chart). The data is from one single course run in two separate sites in the South of England between 2015 and 2016. The course comprised eight 2-2.5 hour sessions held over an eight week period. It was run for a total of five iterations during the data collection period. Course content was designed by a collaboration of peer tutors with lived experience of recovery from mental health problems, clinicians and an academic (also with a past mental health professional background). An adapted version of the Resilience Framework (Hart et al., 2007) was adopted to structure the course. Table 1 shows session titles for each weekly session.

TABLE 1

Building Resilience for Well-being and Recovery course sessions

\begin{tabular}{|l|l|}
\hline Week 1 & Introduction - What is resilience - and what it means to you? \\
\hline Week 2 & Basics \\
\hline Week 3 & Coping \\
\hline Week 4 & Core self \\
\hline Week 5 & Belonging \\
\hline Week 6 & Work and learning \\
\hline Week 7 & Changing the odds \\
\hline Week 8 & Pulling it all together \\
\hline
\end{tabular}

Interview participants were recruited from the first 3 course iterations. Naturally occurring data was derived from all 5 course iterations. Participants' details are presented in table 2. All participants provided signed informed consent. The study was approved as a research project by the university research ethics panel and by the NHS Trust research 
governance panel. Data were analysed using a combined inductive and deductive approach to thematic analysis (Braun \& Clarke, 2006). Deductive elements were informed by the literature research and social learning theory (Wenger, 1998). The first author analysed all the data with other authors independently analysing selected data and then discussing the themes they identified with the first author after which a consensus was reached. 
TABLE 2

Participant details

\begin{tabular}{|c|c|c|c|}
\hline & Interviewees (n=13) & $\begin{array}{l}\text { Participants (providing } \\
\text { 'naturally occurring data' } \\
\text { only) }(\mathrm{n}=47)\end{array}$ & Total Participants 61 \\
\hline \multicolumn{4}{|l|}{ Role } \\
\hline $\begin{array}{l}\text { Tutor (peer, } \\
\text { clinician, } \\
\text { academic) }\end{array}$ & $\begin{array}{l}4 \text { ( } 2 \text { peer, } 1 \text { clinician, } 1 \\
\text { academic) }\end{array}$ & $\begin{array}{l}3 \text { ( } 2 \text { peer tutors, } 1 \\
\text { clinician) }\end{array}$ & $\begin{array}{l}7 \text { ( } 4 \text { Peer tutors, } 2 \\
\text { clinicians, } 1 \text { academic) }\end{array}$ \\
\hline Student & 9 & 45 & 54 \\
\hline \multicolumn{4}{|l|}{ Gender } \\
\hline Female & 9 & 38 & 47 \\
\hline Male & 3 & 11 & 14 \\
\hline \multicolumn{4}{|l|}{ Age } \\
\hline $18-24$ & 0 & 5 & 5 \\
\hline $25-34$ & 2 & 7 & 9 \\
\hline $35-44$ & 3 & 12 & 15 \\
\hline $45-54$ & 2 & 10 & 12 \\
\hline $55+$ & 5 & 11 & 16 \\
\hline Not declared & 1 & 3 & 4 \\
\hline \multicolumn{4}{|l|}{$\begin{array}{l}\text { Highest Educational } \\
\text { Qualifications }\end{array}$} \\
\hline None & & 2 & 2 \\
\hline $\begin{array}{l}\text { GCSE or } \\
\text { equivalent }\end{array}$ & 1 & 13 & 14 \\
\hline $\begin{array}{l}\text { A level or } \\
\text { equivalent }\end{array}$ & 4 & 6 & 10 \\
\hline Degree/HND & 3 & 7 & 9 \\
\hline Higher degree & 2 & 3 & 5 \\
\hline Not declared & 3 & 17 & 21 \\
\hline \multicolumn{4}{|l|}{ First language } \\
\hline English & 11 & 45 & 56 \\
\hline Not English & 2 & 2 & 4 \\
\hline Not declared & & 1 & 1 \\
\hline \multicolumn{4}{|l|}{$\begin{array}{l}\text { Main Current } \\
\text { Occupational Role }\end{array}$} \\
\hline Unemployed & 3 & 10 & 13 \\
\hline $\begin{array}{l}\text { Unemployed re } \\
\text { health }\end{array}$ & 1 & 4 & 5 \\
\hline Sick leave & & 3 & 3 \\
\hline Student & & 1 & 1 \\
\hline Volunteer & & 2 & 2 \\
\hline Paid work & 4 & 9 & 13 \\
\hline Retired & 2 & 2 & 4 \\
\hline Carer & 2 & 4 & 6 \\
\hline Not declared & 1 & 13 & 14 \\
\hline Reported MH Diagnoses & \multicolumn{3}{|c|}{$\begin{array}{l}\text { depression, post traumatic stress disorder, bipolar disorder, anxiety, personality } \\
\text { disorder, schizophrenia, schizo-affective disorder. }\end{array}$} \\
\hline
\end{tabular}




\section{FINDINGS}

Three themes and related sub-themes were identified (see table 3 below).

TABLE 3

Findings

\begin{tabular}{|l|l|}
\hline Overarching Theme & Sub-themes \\
\hline Prior experience and design & Students \\
\cline { 2 - 2 } & Tutors \\
\cline { 2 - 2 } & Structure \\
\hline Co-delivery & Tutors \\
\cline { 2 - 2 } & Co-learner impacts \\
\hline Course Methods and environment & Environment \\
\cline { 2 - 2 } & Homework \\
\cline { 2 - 2 } & Scrapbook \\
\cline { 2 - 2 } & Creative methods \\
\hline
\end{tabular}

\section{Prior experience and design}

\section{Students.}

Students had experienced a broad range of adversities. Consistent with the host Recovery College’s intake, nearly all had personally experienced mental health problems with a small number being carers of people with mental health problems. Some also experienced physical health problems. They described problems with mood, emotion, low motivation, confidence, and cognition, contributing to challenges at home, in work and in past learning experiences. Students had experienced isolation and/or difficulties in relationships - including experiences of stigma (sometimes internalised), discrimination or lack of understanding of mental health problems:

I was medically retired .... My doctor said ... you'll never work full time again. And I laughed .. But he was proved right. .... I still can't appreciate there's anything wrong with me. I think I'm a fraud [...] I think big brother is watching because I've got a blue badge, and I'm convinced somebody's going to take a photograph and I'm going to appear in the papers. (Student1)

\section{Tutors}

Peer tutors brought lived experience of mental health challenges to the course design. This was achieved by their active participation in course planning meetings in which they applied their experiential knowledge to inform both the overall structure of the course and specific session plans and learning activities. This was highly valued by other tutors and 
students: “It worked really well ... it's so much easier if you've walked in those person’s shoes” (Student2). One peer tutor explained this enabled them to suggest strategies for students: “For me it’s embedded ... I don’t have to consciously think 'OK what coping skill do I need to use in this situation?’” (PeerTutor1).

This complimented the clinicians' and academic’s expertise. A clinician considered her professional skills as an occupational therapist equipped her to use creative methods and work with the concept of adaptation to support resilience. She reminded herself "the whole point of the Recovery College is that they're educational groups, they're not therapy” (Clinician1). However, she added that therapeutic skills did have a role to play both in supporting people should they become distressed and as a source of knowledge that she could use in teaching.

From preparatory training and as tutors on other courses, the peer tutors brought experiences of collaboration with clinicians. The clinician interviewed for the study drew on experiences of working with peers in other roles. Likewise the academic's applied research practice had become increasingly collaborative. The clinician and peer tutors felt they were genuinely respected and equal contributors to course design and review. Central to achieving this was a principle that planning and review meetings required the presence of at least one clinician, peer tutor and academic and that all should review and discuss evaluation documentation, though the academic noted that:

\footnotetext{
A number of times during the early sessions I was referred to by the peer tutors or clinicians as being 'the expert' and there was that denigration of their own expertise .... I had to work with ... reinforcing ... that also they have expertise too pointing to specific examples from their lived experience or professional practice. Over time [this] moved towards genuine mutual recognition that these are different types of expertise. (Academic1)
}

This contributed to challenging perceived and actual power imbalances associated with academic, lived experience and practitioner roles. Since all forms of expertise were recognised it became important for the collaborators to ensure that the language and 
terminology they used were mutually understandable. These processes may have been helped by the majority of planning and review meetings being held in café's rather than academic or professional spaces.

Tutors all brought experiences of active learning: the academic from problem based learning approaches, the peer tutors from preparatory training, and, clinicians from using educational strategies in their mental health practice.

\section{Structure}

The course evolved in response to evaluation of each iteration. The session length was shortened from 2.5 to 2 hours and the session order was adapted so that the 'Coping' session came earlier with a view to providing students with practical resources they could subsequently use. The detailed Recovery College session template facilitated the structure, content identification and role allocation.

\section{Co-delivery}

\section{Tutor approach}

Benefits of the educational approach and collaboration emerged strongly from the data. This included appreciation from students with more limited and/or troubling past learning experiences:

You'd got people who have got all the academic training mixing with the clinician types who've worked with people like myself, and you've got the peer trainers who've ... got the lived experience side of things, and it's a really good blend. (Student3)

Students felt increased empowerment and confidence: “I’ve managed to build up my confidence and my own faith in myself and proved that I can do things again” (Student4). Challenges of working across different boundaries within sessions were raised by tutors and students, particularly when this related to expertise not represented in the course team (e.g. medication advice). 
Peer tutors were viewed as being approachable: “If somebody’s upset ... [the peer tutors] will be able to deal with it more” (Student5). The peer tutors' combination of knowledge, skills and personal style was seen as inspiring and encouraging and as fostering hope and motivation. Students noted that, in contrast to some previous experiences, they found the clinicians to be both "knowledgeable ... and supportive ... instead of talking me down” (Student6). This may have been helped by the inclusion of peer tutors’ lived experience encouraging the clinicians and academic to draw on some of their own personal experiences. This consequence of coproduction in turn helped them to consider more deeply how their academic and practice related skills and approach may be experienced and felt by students. Many comments about the academic contribution were similar to those relating to clinicians but with additional emphasis on the credibility that university involvement brought and the importance of sharing evidence:

[the academic]'s input ... I found very useful.... I think that if I were at university studying it ... it would be very much of this type of structure, where you're taking a particular heading and you are exploring that heading in reasonable depth. (Student7)

Students and peer tutors also stated they valued the academic's ability to actively engage students in discussion and thinking:

“He's brilliant at listening, understanding where the other person's coming from and then exploring that.... I know he's a lecturer, but he never lectures.... He gets everybody involved. (PeerTutor2)

\section{Co-learner impacts}

Benefits of the collaborative approach were also apparent in the impact that students had on each other. Students felt a sense of camaraderie and relief at realising “that you're not the only one” (Student4). This became a source of inspiration and practical advice:

There are also people ... that can teach you things about how they cope.... It's like a really rich tapestry, ... it's never just about an illness.... And hearing other people say similar things, but about different illnesses and different situations, it's only going to make you a fuller person. (Student8) 


\section{Course methods and environment}

\section{Environment}

Use of table-based discussion was appreciated as was the generally educational and comfortable décor. A challenge was that at one site the course had to be held in a community mental health base whereas the other site was in a public library meeting room:

\footnotetext{
The environment has a massive [impact...] In [the public library] it felt like you were in an educational environment.... It felt much more relaxed and everyone felt equal. In the mental health establishment ... it felt ... not quite so easy for people to talk ... because people are often coming from their own perceptions of themselves as a mental health service user and that can have an impact. (Clinician1).
}

\section{Methods}

Participants commented on how the methods (eg pair work, post-it notes and whole group discussion) supported participation of people of diverse ages, cultures and other backgrounds. Verbal and non-verbal methods were used with an emphasis on active discussion and activities rather than didactic teaching. Students felt respected and gently encouraged to engage: "If you wanted to you could contribute, if you felt you couldn’t you didn’t have to" (Student4).

Homework and scrapbooks supported learning. Completing homework enabled some who had not felt able to fully join session discussions to still participate: "I was able to at least do things at home ... to give me the essence of what the course was about.” (Student2). Students discussed their tasks with family and friends and this contributed to reinforcing their learning. At the beginning of each session students shared feedback on homework enabling them to learn from each other.

The scrapbook was a reference point containing images and notes from the course that some used to refer to when feeling distressed:

[It] is something to look at ... when I'm down.... I will think about all these things and so say yes, this was what I learned from here.... I can think of where to go for help and I do. (Student5) 
Some students felt comfortable using creative approaches (such as drawing, collage, producing a 'self-soothing box' and selecting music) - for two interviewees whose first language was not English it felt preferable to verbal or written tasks:

having a scrapbook for me was the expression of my heart.... I can't express it in language my command ... - I don't think it's very good. So for me to just paste [pictures of] what I see and things ... is very important. (Student5)

Other students were more hesitant yet were still successfully encouraged to engage in such activities: “resources like music or,[...the] calming box ... things like that I never really thought of using, but it's part of my resilience now too” (Student6).

\section{DISCUSSION}

Effective collaboration between tutors emerged as a key aspect of the course's success. As in the limited Recovery College literature (Dunn et al., 2008; Meddings et al., 2014; Perkins et al., 2012) this involved bringing together peer tutors' lived-experience expertise with mental health practitioner knowledge. Our findings additionally draw attention to the contribution of academic knowledge and peer tutors' teaching skills (derived from preparatory training). Furthermore, we found evidence that the use of lived experience expertise was not confined to that shared by peer trainers. The valuing of lived-experience on a par with practitioner and academic knowledge meant that the practitioners and academic felt it legitimate to draw on relevant aspects of their own lived experience. Our findings provide empirical evidence for Perkins et al.’s (2012) guidelines endorsing the value of peer support from fellow learners. This area has to date only received limited research attention (Meddings et al., 2014). Thus the course made extensive use of students' lived-experience expertise to educate each other with homework playing an important part in this. This seemed to help students overcome feelings of isolation and self-stigma that can arise from internalising wider societal negative attitudes towards people with mental health problems (Brohan et al., 2010). 
Boundaries between diverse roles, experiences and knowledge domains of the different tutors and students were apparent. However, they did not become barriers to learning. Consistent with developments in social learning theory (Wenger-Trayner \& Wenger-Trayner, 2014), they were effectively harnessed to promote learning. Boundaries only appeared as insurmountable when issues arose relating to knowledge domains not represented on the course (eg medication). A solution to this may lie in inviting individuals with relevant expertise into specific sessions. Alternatively if Recovery Colleges achieved aspirations (Kelly et al., 2017; Perkins et al., 2012) to recruit a broad range of mental health service users, carers, practitioners and general public - such expertise may find itself in the room more naturally (obviously with provisos that people will always need to have individual discussions about some issues).

Oh (2013) identified a connection to Transformative Learning Theory in the empowerment and enhanced critical reflection experienced by Recovery College students and this accorded with students’ experiences in our study. Oh (2013) concluded that “Recovery Colleges look nothing like what we normally see in places of learning." However the academic in our study found strong links between his Recovery College teaching and University based use of active learning approaches such as Problem-Based Learning. Such approaches are consistent with Transformative Learning Theory and evidence suggests they are becoming increasingly widespread in higher education (Gewurtz, Coman, Dhillon, Jung, \& Solomon, 2016). This growth further strengthens the case for more active involvement of Universities in Recovery Colleges. The peer tutors’ preparatory training helped them in turn adopt active learning approaches. We also found that the clinicians had relevant experience to draw on in the form of approaches to supporting self-management which Slade et al. (2014) have identified as contributing to empirically supported pro-recovery inventions. 
This article's introduction noted that academic involvement is not common in English Recovery Colleges. As McCaig et al. (2014) suggested academic involvement in the course may have helped to reinforce its educational emphasis. It may have also helped to manage challenges of proving courses that are inclusive of students’ diverse learning styles and levels raised as concerns by Burhouse et al. (2015) and Meddings et al. (2014). Higher education across the world is increasing concerned to ensure active engagement in society beyond the confines of Universities to make meaningful impacts in areas such as public health and wellbeing (Moore, 2014). Were academic involvement to be broadened across Recovery Colleges this also may help meet the goal (Perkins et al., 2012) of having a wider range of students attending courses because it might further strengthen their educational credibility and increase publicity networks.

Creative methods helped maximise active participation by students in a manner consistent with both mental health (Caddy et al., 2012) and pedagogical (Lehr \& Schlenger, 2016) research. This was enacted with flexibility and sensitivity to students' preferences and past experiences. Flexibility was balanced with detailed course session outlines that structured sessions and were a reference point for course evaluation.

On one site holding the course in a mental health setting, as opposed to a more mainstream setting, may have partially undermined attempts to reinforce the educational identity of students (as opposed to a service user identity). This finding supports Recovery College guidance and empirical findings (Burhouse et al., 2015; McGregor et al., 2014; Perkins et al., 2012) and accords with broader theory about the influence of environment on the role identification of mental health service users (Jacob et al., 2016). Again, there is a potential role here for universities to play in providing learning spaces that reinforce educational identities of students. 
According to Winship (2016) ‘New Recovery’ approaches, such as Recovery Colleges, are 'fit for austerity' (p71) because of their emphasis on mobilising assets beyond professional services (thereby making them cheaper). Whilst our course did indeed mobilise assets beyond professional services, like other Recovery College courses, it also involved input from mental health practitioners. This is consistent with Flegg et al.’s (2015) findings from a regional UK survey of 131 receivers and providers of peer-to-peer services in which a strong view emerged that such services should provide additional, as opposed to alternative, support to traditional services. Slade et al. (2014) argues it is an abuse of recovery values to use a recovery orientation to justify closing services. So, rather than heralding an austerity led demise of traditional mental health services, Recovery Colleges may indicate a new way forward for collaborative mental health practice. Such a trajectory would be consistent with Beckwith et al.’s (2016) argument that the recovery movement can be seen to represent a form of prefigurative politics in its challenges to professional power over treatment and control over health related knowledge. Research by Walker and colleagues on the embedded everyday mental health practices of non-clinical organisations also points to the importance of informal spaces in supporting mental ill-health (Walker et al., 2017). The Recovery College movement also challenges dominant discourses which have been criticised for unduly making individuals responsible for their recovery and thus used to justify withdrawal of mental health support (Hart et al., 2016; Stuart et al., 2017). Indeed, Piat et al.’s (2016) account of a community of practice which developed Recovery College proposals suggests a strong commitment to recovery values may well help collaboration in the face of financial pressures.

\section{Limitations}

We believe this is the first published study that analyses in detail experiences of collaborators involved in any one specific Recovery College course. This provides a 
significant depth of insight into mechanisms that may support effective Recovery College collaboration. Limitations exist, partly as a consequence of this focus. Notably, the study was restricted to one Recovery College in one geographic area (albeit over 2 different sites and across various cohorts), thus processes of collaboration may vary in different areas and with different population mixes.

\section{CONCLUSION}

A strong commitment to collaboration in design and delivery of Recovery College courses can help mobilise the diverse experiences and expertise of the tutors and of the students. The environment and methods of learning have a significant impact and should be considered carefully alongside content. Boundaries between people and areas of knowledge and experience that arise in design and delivery can be viewed as sources of creativity that can enrich courses rather than serve as barriers. Further research could investigate these processes, across different Recovery College courses in a range of different settings. It could also explore the existence and impact of the varied categories of participants and of the payment rates and contracts of the inputting tutors.

Word Count $=4000$

\section{ACKNOWLEDGEMENTS}

The authors extend their sincere thanks to the participants who took the time to participate in these interviews and/or share products from the course design and delivery and share their thoughts and opinions. We also thank Katharine Pople, Sarah Mead and Dr Kay Aranda for conducting the interviews, as well as all Imagine Programme - Social Context group members including lived experience experts, academics, community partners, practitioners, and policy-makers for contributing ideas and support. Finally, we would like to 
thank the anonymous journal article reviewers for their constructive comments and suggestions.

\section{DECLARATION OF INTEREST}

The authors report no conflict of interest. This research received some support from the University of Brighton, Centre for Health Research Internal Research Grant and from the Imagine Programme funded by grant ES/K002686/2 from the Economic and Social Research Council (ESRC). The contents are solely the responsibility of the authors and do not necessarily represent the official view of the ESRC. Information on ESRC is available on http://www.esrc.ac.uk/.

\section{REFERENCES}

Anthony, W. A. (1993). Recovery from mental illness: The guiding vision of the mental health system in the 1990's. Innovations and Research, 2(3), 17-24.

Ashcraft, L., Anthony, W. A., \& Dayan, E. (2006). Moving recovery into the classroom. Behavioral Healthcare, 26(5), 10-10, 12.

Beckwith, M., Bliuc, A.-M., \& Best, D. (2016). What the recovery movement tells us about prefigurative politics. Journal of Social and Political Psychology, 4(1), 238-251.

Braun, V., \& Clarke, V. (2006). Using thematic analysis in psychology. Qualitative Research in Psychology, 3(2), 77-101.

Brohan, E., Slade, M., Clement, S., \& Thornicroft, G. (2010). Experiences of mental illness stigma, prejudice and discrimination: a review of measures. BMC Health Services Research, 10(1), 80.

Burhouse, A., Rowland, M., Marie Niman, H., Abraham, D., Collins, E., Matthews, H. Denney, J., Ryland, H. (2015). Coaching for recovery: a quality improvement project in mental healthcare. BMJ Quality Improvement Reports, 4(1). 
Caddy, L., Crawford, F., \& Page, A. C. (2012). 'Painting a path to wellness': correlations between participating in a creative activity group and improved measured mental health outcome. Journal of Psychiatric and Mental Health Nursing, 19(4), 327-333.

Cameron J, Hart A, Eryigit-Madzwamuse, Neale P, Reardon M, Brooker S. (forthcoming). Outcomes of a resilience building mental health Recovery College course: a mixed methods study.

Department of Health. (2011). No Health without Mental Health: a Cross-Government Mental Health Outcomes Strategy for People of all Ages. London: HM Government.

Dunn, E. C., Sally Rogers, E., Hutchinson, D. S., Lyass, A., MacDonald Wilson, K. L., Wallace, L. R., \& Furlong-Norman, K. (2008). Results of an innovative university-based recovery education program for adults with psychiatric disabilities. Administration and Policy in Mental Health and Mental Health Services Research, 35(5), 357-369.

Flegg, M., Gordon-Walker, M., \& Maguire, S. (2015). Peer-to-peer mental health: a community evaluation case study. The Journal of Mental Health Training, Education and Practice, 10(5), 282-293.

Gewurtz, R. E., Coman, L., Dhillon, S., Jung, B., \& Solomon, P. (2016). Problem-based learning and theories of teaching and learning in health professional education. 4(1), 59-70.

Gill, K. H. (2014). Recovery colleges, co-production in action: The value of the lived experience in "learning and growth for mental health". Health Issues, 113, 10-14.

Hart, A., Blincow, D., \& Thomas, H. (2007). Resilient Therapy: Working with Children and Families. London: Routledge.

Hart, A., Gagnon, E., Eryigit-Madzwamuse, S., Cameron, J., Aranda, K., Rathbone, A., \& Heaver, B. (2016). Uniting resilience research and practice with an inequalities approach. SAGE Open, 6(4).

Imagine Project (2017) Imagine Project. Connecting communities through research. http://www.imaginecommunity.org.uk/ [Accessed on 09.09.2017]. 
Jacob, J. D., Perron, A., \& Corneau, P. (2016). Structural othering: Towards an understanding of place in the construction of disruptive subjectivities. In D. P. Holmes, D. Holmes, \& J. D. Jacob (Eds.), Power and the Psychiatric Apparatus: Repression, Transformation and Assistance (pp. 149-163). London : Routledge Ltd.

Kelly, J., Gallagher, S., \& McMahon, J. (2017). Developing a recovery college: a preliminary exercise in establishing regional readiness and community needs. Journal of Mental Health, 26(2), 150155.

Lehr, S., \& Schlenger, A. (2016). Creative strategies to enhance students' classroom learning in mental health. Journal of Psychosocial Nursing and Mental Health Services, 54(5), 41-48.

McCaig, M., McNay, L., Marland, G., Bradstreet, S., \& Campbell, J. (2014). Establishing a Recovery College in a Scottish University. Mental Health and Social Inclusion, 18(2), 92-97.

McGregor, J., Repper, J., \& Brown, H. (2014). "The college is so different from anything I have done". A study of the characteristics of Nottingham Recovery College. The Journal of Mental Health Training, Education and Practice, 9(1), 3-15.

Meddings, S., Guglietti, S., Lambe, H., \& Byrne, D. (2014). Student perspectives: recovery college experience. Mental Health and Social Inclusion, 18(3), 142-150.

Meddings, S., McGregor, J., Roeg, W., \& Shepherd, G. (2015). Recovery colleges: quality and outcomes. Mental Health and Social Inclusion, 19(4), 212-221.

Moore, T. L. (2014). Community-university engagement: A process for building democratic communities. ASHE Higher Education Report. 40(2): 1-129.

Newman-Taylor, K., Stone, N., Valentine, P., Hooks, Z., \& Sault, K. (2016). The Recovery College: A unique service approach and qualitative evaluation. Psychiatric Rehabilitation Journal, 39(2), 187-190.

Oh, H. (2013) The pedagogy of recovery colleges: clarifying theory. Mental Health Review Journal 18 (4). 
Perkins, R., Repper, J., Rinaldi, M., \& Brown, H. (2012). Recovery Colleges. London: Centre for Mental Health, NHS Confederation. Available from:

https://www.centreformentalhealth.org.uk/recovery-colleges-paper [Retrieved February 12 2017].

Piat, M., Briand, C., Bates, E., \& Labonté, L. (2016). Recovery communities of practice: An innovative strategy for mental health system transformation. Psychiatric Services, 67(1), 10-12.

Repper, J. \& Perkins, R. (2012). Recovery: a journey of discovery for individuals and services. In P. Phillips, T. Sandford, \& C. Johnston (Eds.), Working in Mental Health: Practice and Policy in a Changing Environment (pp. 71-80). London: Routledge.

Shepherd, G., Boardman, J., Rinaldi, M., \& Roberts, G. (2014). Supporting Recovery in Mental Health Services: Quality and Outcomes - ImROC Briefing Paper No. 8. London: Centre for Mental Health and Mental Health Network, NHS Confederation. Available at: https://www.centreformentalhealth.org.uk/recovery-quality-and-outcomes [Retrieved January 72017$].$

Silverman, D. (2011). Interpreting Qualitative Data. (2 ${ }^{\text {nd }}$ edition). London: Sage.

Slade, M., Amering, M., Farkas, M., Hamilton, B., O'Hagan, M., Panther, G. Perkins, R., Shepherd, G., Tse, S., Whitley, R. (2014). Uses and abuses of recovery: implementing recovery-oriented practices in mental health systems. World Psychiatry, 13(1), 12-20.

Stuart, S.R., Tansey, L, \& Quayle, E. (2017) What we talk about when we talk about recovery: a systematic review and best-fit framework synthesis of qualitative literature. Journal of Mental Health 26: 291-304.

Ungar, M., Brown, M., Liebenberg, L., Othman, R., Kwong, W. M., Armstrong, M., \& Gilgun, J. (2007). Unique pathways to resilience across cultures. Adolescence, 42(166), 287-310.

Walker, C., Hart, A., \& Hanna, P. (2017). Towards a new Community Psychology of Mental Health: Spaces, Places, People and Activities. London: Palgrave.

Wenger-Trayner, E., \& Wenger-Trayner, B. (2014). Learning in a landscape of practice: A framework 
In E. Wenger-Trayner, M. Fenton-O'Creevy, S. Hutchinson, C. Kubiak, \& B. Wenger-Trayner (Eds.), Learning in Landscapes of Practice: Boundaries, Identity, and Knowledgeability in PracticeBased Learning (pp. 13-29). London: Routledge.

Wenger, E. (1998). Communities of Practice: Learning, Meaning, and Identity. Cambridge: Cambridge University Press.

Winship, G. (2016) A meta-recovery framework: positioning the 'New Recovery' movement and other recovery approaches. Journal of Psychiatric and Mental Health Nursing, 23(1): 66-73.

Zabel, E., Donegan, G., Lawrence, K., \& French, P. (2016). Exploring the impact of the recovery academy: a qualitative study of Recovery College experiences. The Journal of Mental Health Training, Education and Practice, 11(3), 162-171.

Zucchelli, F. A., \& Skinner, S. (2013). Central and North West London NHS Foundation Trust's (CNWL) Recovery College: the story so far .... Mental Health and Social Inclusion, 17(4), 183-189. 